\title{
Methodology and potential of image analysis and unconventional use of GIS tools in determining grain size distribution and fractal dimension: a case study of fault rocks in the Western Tatra Mts. (Western Carpathians, Poland)
}

\author{
Maciej KANIA ${ }^{1, *}$ \\ 1 Jagiellonian University, Institute of Geological Sciences, Gronostajowa 3a, 30-387 Kraków, Poland
}

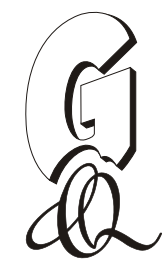

\begin{abstract}
Kania, M., 2019. Methodology and potential of image analysis and unconventional use of GIS tools in determining grain size distribution and fractal dimension: a case study of fault rocks in the Western Tatra Mts. (Western Carpathians, Poland). Geological Quarterly, 63 (2): 345-358, doi: 10.7306/gq.1468
\end{abstract}

Associate editor: Jacek Grabowski

A methodology of textural analyses based on image analysis is proposed and tested based on study of fault rock samples from the Tatra Mts., Poland. The procedure encompasses: (1) SEM-BSE imagery of thin sections; (2) image classification using the maximum likelihood method, performed with GIS software; (3) statistical analysis and fractal dimension (self-similarity) analysis. The results of this method are comparable to those obtained with methods involving specialized software. The proposed analytical procedure particularly improves qualitative observations with quantitative data on grain shape and size distribution. The potential of the method is shown, as an auxiliary tool in determining the nature of deformation processes: the role of high-temperature dynamic recrystallization processes is recorded using grain shape indicators, whilst the switch from ductile to brittle conditions is reflected by the grain size distribution pattern.

Key words: petrotectonics, image analysis, GIS, mylonites, cataclasites, Tatra Mts.

\section{INTRODUCTION}

The method most usually applied in petrotectonics is the analysis of three-dimensional structures in two-dimensional sections, especially petrological thin sections. Sections can be studied by many different methods (e.g., optical microscopy, cathodoluminescence, scanning or transmission electron microscopy), but the result is always an image. In fact, such an image may be considered a map of distribution of any measurable parameter, such as light intensity and colour, or other signal level reflected by the sample surface. Such a map is a source of a great deal of microstructural and microtextural data, especially concerning grain size distribution and grain shape. Detailed analyses of such features must be conducted on the basis of a statistically significant amount of data, which can be obtained either manually or via computer-aided measurements.

This paper explores selected potential uses for the application of computer image analysis in petrotectonics involving rocks related to shear zones. These methods were developed by researchers including. Heilbronner (2000), who proposed the Lazy Grain Boundary method, a macro working with NIH or

\footnotetext{
*E-mail: maciej.kania@uj.edu.pl
}

Received: November 14, 2018; accepted: March 13, 2019; first published online: May 20, 2019
Scion Image software which detects grains in thin sections. Heilbronner and Keulen (2006) applied widely-known photo editing software (Adobe Photoshop) to pre-processing, followed by a specialised set of ImageSXM macros working in the Mac OS $X$ operating system. The input images they applied were SEM/BSE scans; the output data consisted of a collection of shape factors for grains detected in fault gouges.

However, Geographical Information Systems (GIS) software appears to be an excellent alternative to specialised image analysis software. GIS software contains a set of toolboxes originally prepared for processing satellite imagery land-use classification (using well-known digital methods) or landscape metrics (tools applying numerical descriptions of landscape structures obtained from aerial or satellite imagery; see e.g. Gökyer, 2013) as well as for basic operations such as the conversion of raster images to vector shapefiles. An example of this type of application of GIS methodology was provided by Tarquini and Favalli (2010) in the form of the concept of a GIS-based "microscopic information system", or MIS, which is a tool set for innovative petrographic analyses conducted on substantial data sets. Determination of quartz optical axes in thin section images is another potential application for GIS software in microstructural petrographic research (Hassanpour, 2012).

The motivation to perform this study was to explore whether it is possible to carry out thin section image analyses using relatively simple methods, while providing interesting results with the potential for novel interpretations. 
In the present study, a combination of photo-editing software and ESRI ArcGIS/ArcMap was selected for grain size distribution analyses of SEM-BSE images. Particularly nowadays, when GIS software is popular with and familiar to most earth science researchers and students, the prospects for such unconventional applications are good.

The present study shows how image analyses based on GIS can be applied in microstructural analyses. As regional geology studies are limited in their interpretational potential, the methodology proposed may be considered for inclusion into multi-proxy geological studies.

Selection of the samples was based on an earlier paper (Kania, 2014), enabling reference to earlier shape analyses performed with optical microscopy and manual grain vectorisation. All of the samples are from the Western Tatra Mts., from shear zone-related rocks.

\section{GEOLOGICAL SETTING}

The Tatra Mountains is an Alpine collisional fold belt formed due to Late Cretaceous nappe thrusting and Cenozoic uplift (for detailed review see Jurewicz, 2005; Śmigielski et al., 2016). The crystalline core of the Western Tatras, on which this paper is focused, is composed of a metamorphic complex cut with numerous igneous intrusions. According to a widely accepted interpretation (e.g., Kahan, 1969; Janák, 1994), it includes two structural units with inverted metamorphism: an upper unit with gneiss, migmatites, and amphibolites, and a lower unit containing metasedimentary rocks with protolith sedimentation dated to the Late Cambrian (Kohút et al., 2008). This structure was formed during Variscan tectonic episodes (Fritz et al., 1992). The upper and lower units were identified in the Polish Western Tatra Mts. forming respectively a migmatitic complex and a metasedimentary complex with amphibolites (Gawęda and Burda, 2004). The younger component of the crystalline core comprises igneous rocks. There are three granite varieties that intruded during the subduction (365-360 Ma) and collision (340-332 Ma) events of the Variscan orogeny: (1) biotite-amphibole-quartz diorite, (2) a "High Tatra type" biotite-muscovite granodiorite transitional to tonalite and (3) a "common Tatra type" biotite-muscovite porphyric granodiorite (Kohút and Janák, 1994; Kohút et al., 2008; Gawęda, 2008). Variscan mylonitization was active before $298 \mathrm{Ma}$ (Deditius, 2004), whilst the Alpine deformation was discussed by Cymerman (2009).

\section{SAMPLING}

The samples were taken from several areas in the western part of the Western Tatras (Fig. 1 and Table 1). This area is dominated by leucogranites, mylonites and, in the Wołowiec
(Slovakian: Volovec) Mt. area, granodiorites (Skupiński, 1975; Bac-Moszaszwili et al., 1979; Piotrowska, 2016). The characteristic feature of this region is the abundance of sub-horizontal brittle-ductile shear zones, composed of shearing-related rocks: cataclasites and mylonites. The shear zones show various grades of deformation, with overprinting by a range of kinematic structures (Cymerman, 2010; Kania, 2014).

The samples (Table 1 and Fig. 2) comprise different rock types; however, for the sake of consistency, all of the rocks were collected from shear zones. The mylonites (samples Za2, 72,68 ) are composed of quartz porphyroclasts embedded in a layered matrix. Sample Za2 contains bands of white mica that forming the dominant directional structure. The matrix is composed of a fine-grained quartz-dominated aggregate. The other mylonite sample, 72 , is characterized by a matrix dominated by sericite. The third (68) mylonite sample is characterized by highly recrystallized zones dominated by white and dark micas. These blastomylonitic zones forms foliation layers between slightly deformed plagioglase and quartz crystals.

The cataclasites (samples 58 and 43) are dominated by plagioclase and quartz. The cataclasite sample 58 is an S-C cataclasite (Lin, 1999, 2001); the analyses concentrated on the layer composed of biotite, muscovite, plagioclase, and quartz, located in a granitic-type setting. Cataclasite sample $43 \mathrm{com}-$ prises a block-controlled cataclasite, adapting the terminology proposed for quartzite cataclasites by Ismat and Mitra (2005), the latter being characterised by a more abundant sericite matrix developed mainly in fractures.

\section{METHODS}

The analytical procedure shown in Figure 3 can be subdivided into 5 stages, reflecting the applied input/output data format and software. The first stage was carried out with Hitachi SEM Manager software, the second with the Corel Paint Shop Pro 8 photo editor. The third and fourth stages used ESRI ArcGIS suite 10.2 (ArcMap application); the fifth and final stage was carried out with StatSoft Statistica 12 and the $R$ statistical computing language. All of the analyses were performed in the Windows 10 environment.

The backscattered electron (BSE, see Fig. 3, step 1.1; Fig. 4A) images were acquired as $2560 \times 1920$-pixel, uncompressed, 8-bit (256 grey levels recorded) tiff bitmaps, using a Hitachi S-4700 scanning electron microscope equipped with a YAG detector at an acceleration voltage of $20 \mathrm{kV}$ (Jagiellonian University in Kraków, Institute of Geological Sciences, SEM laboratory) with constant $250 \times$ magnification. Noise reduction and image softening (both functions of the Corel PaintShop Pro application) were applied (steps 2.1 and 2.2) to eliminate the "salt-and-pepper" look. If necessary ( 2.3 decision step), the procedure was repeated (no more than one additional pass). The

Samples analysed in the study

\begin{tabular}{|l|c|c|c|}
\hline Symbol & Locallity & $\begin{array}{c}\text { Dominant } \\
\text { deforma- } \\
\text { tion type }\end{array}$ & Remarks \\
\hline 43 & Ornak Ridge & brittle & cataclasites with a low content of matrix, mainly sericite and in some enclaves feldspathic \\
\hline 58 & Dziurawa Pass & brittle & protocaclasite with initial grain reduction, with large (over 1 mm) plagioclases \\
\hline 68 & Siwa Pass & ductile & mylonitic gneiss, with deformation localized in the mica-enriched bands \\
\hline 72 & Siwa Pass & ductile & mylonite with high content of sericitic matrix \\
\hline Za2 & Zabrat' Pass & ductile & ultramylonite with feldspathic/quartz matrix and mica bands \\
\hline
\end{tabular}



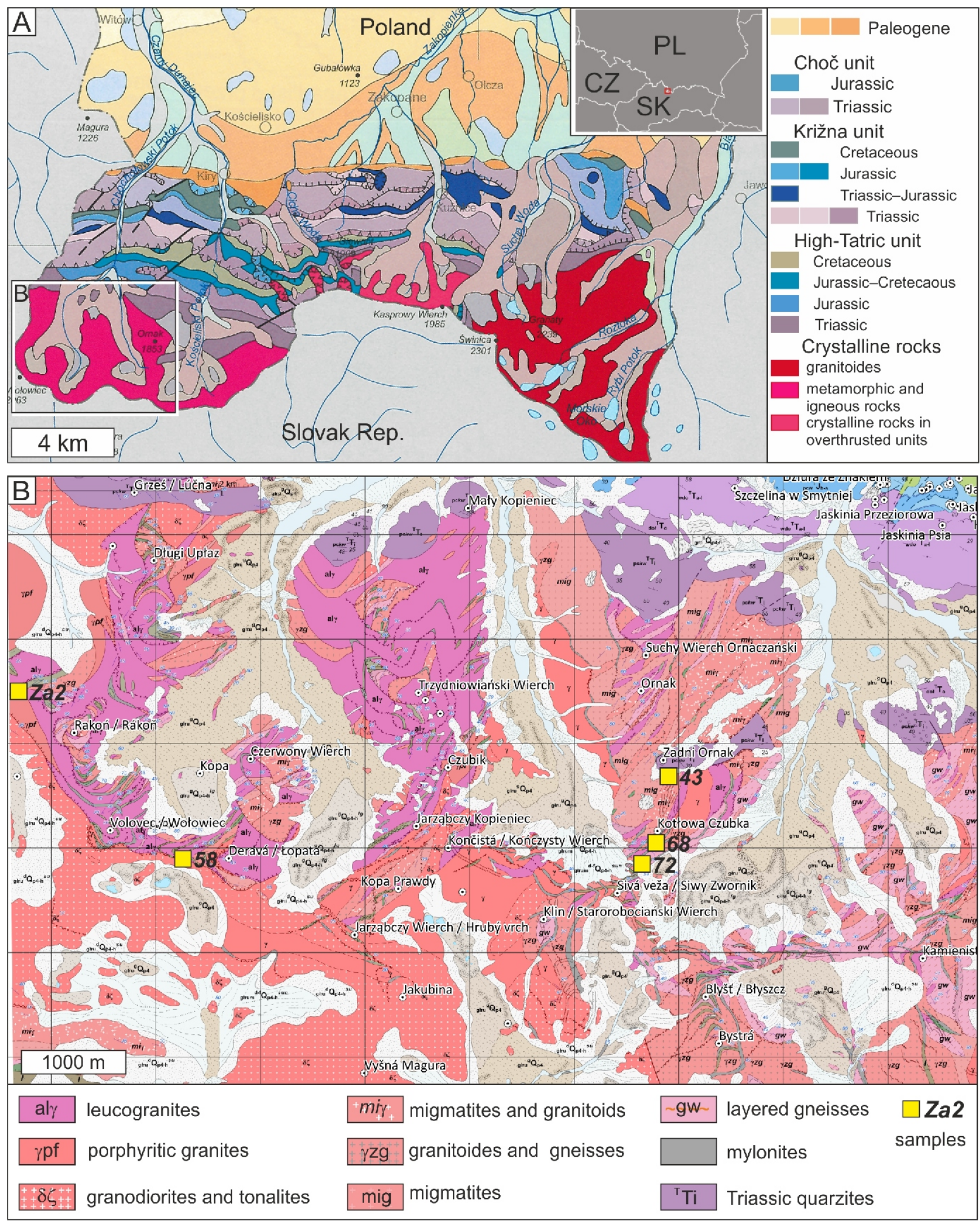

Fig. 1. Geological map of the area sampled

A - general geological map of the Polish Tatra Mts. (after Nawrocki and Becker, 2017, modified); B - detailed map based on Piotrowska (2016) via the PGI WMS server 

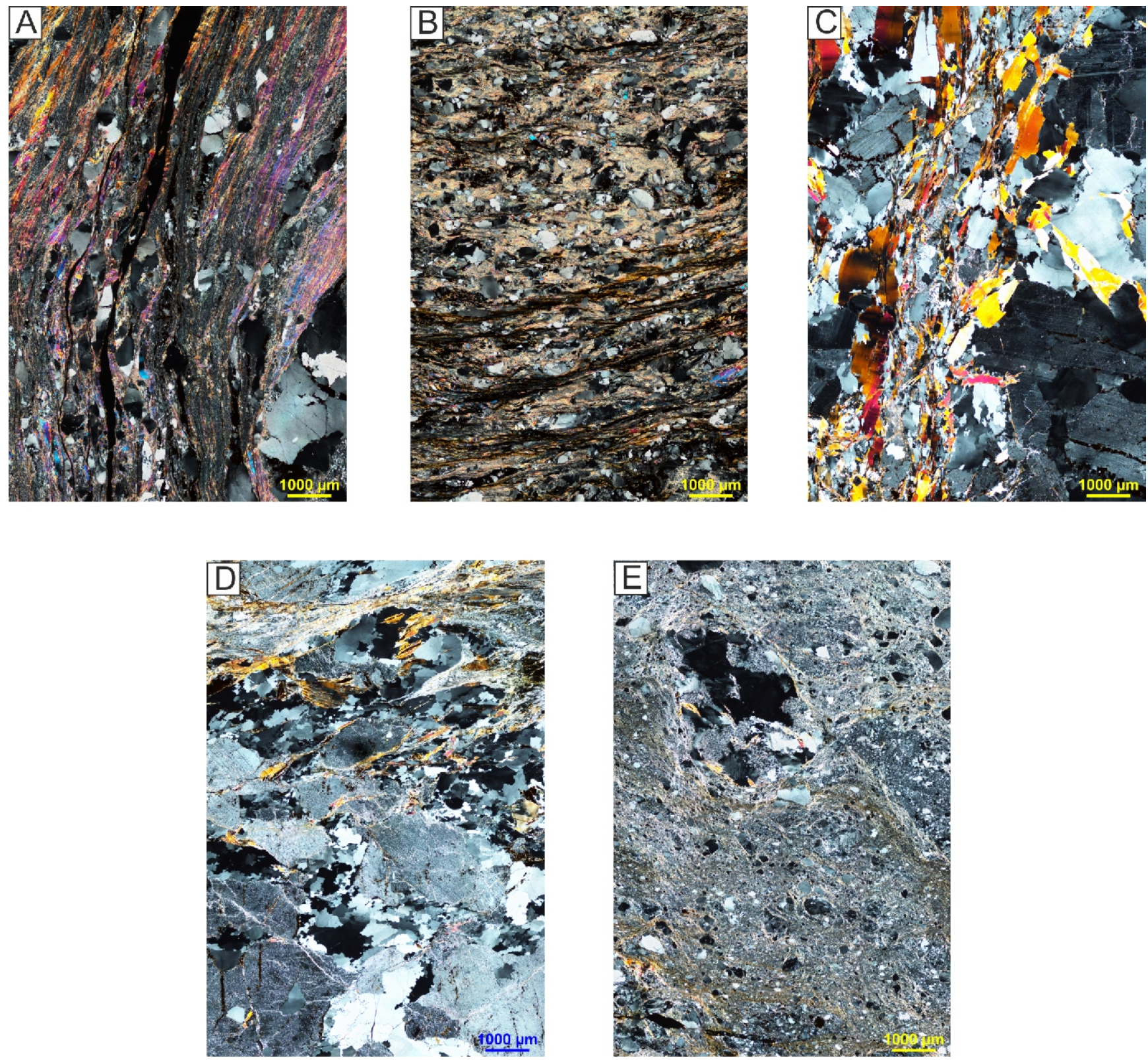

Fig. 2. An overview of the structure of selected samples

A - sample Za2, mylonite; B - sample 72, mylonite; C - sample 68, mylonite; D - sample 58, cataclasite; E - sample 43, cataclasite; all photos are in crossed polarized light

pre-processed bitmap was loaded into ESRI ArcGIS ArcMap without defining a coordinate system (in fact, the simplest Cartesian coordinates were used, with one pixel as the applicable unit). Training polygons were defined (step 3.1) as $\sim 10$ in quartz, 5 in feldspar, and 5 in matrices, in order to conduct a supervised classification in accordance with the maximum likelihood classification method. However, the effective number of defined categories varied, and in some cases additional classes (i.e. grain border zones) were marked. Additional polygons were marked for zones outside the thin section area or for holes in the thin section, defined as a special "no-data" class.

The maximum likelihood classification method applied is a popular image classification algorithm in which a probability function is calculated for each defined class using pre-defined training data. Each of the pixels analysed is assigned to one of the classes based on a statistical probability calculation (e.g., Sun et al., 2013).

Output images (rasters) of maximum likelihood classification (see e.g., step 3.2; Fig. 4B) were evaluated (decision step 3.3). The evaluation result was considered positive if groups of pixels clearly corresponded to grains, negative if the classified image included too much noise or if grains were not clearly recognisable in the matrix. In the case of a negative evaluation, the analyses were repeated, beginning with step 2.1 or 3.1.

The classified images required additional corrections in order to render the grain surfaces more homogenous. These are steps 3.4 and 3.5, repeated depending on the result of decision step 3.6.

The raster images were then vectorised (step 3.7) and processed further as ESRI shapefiles (shp). Grains with grid codes corresponding to quartz were chosen and the smallest grains 


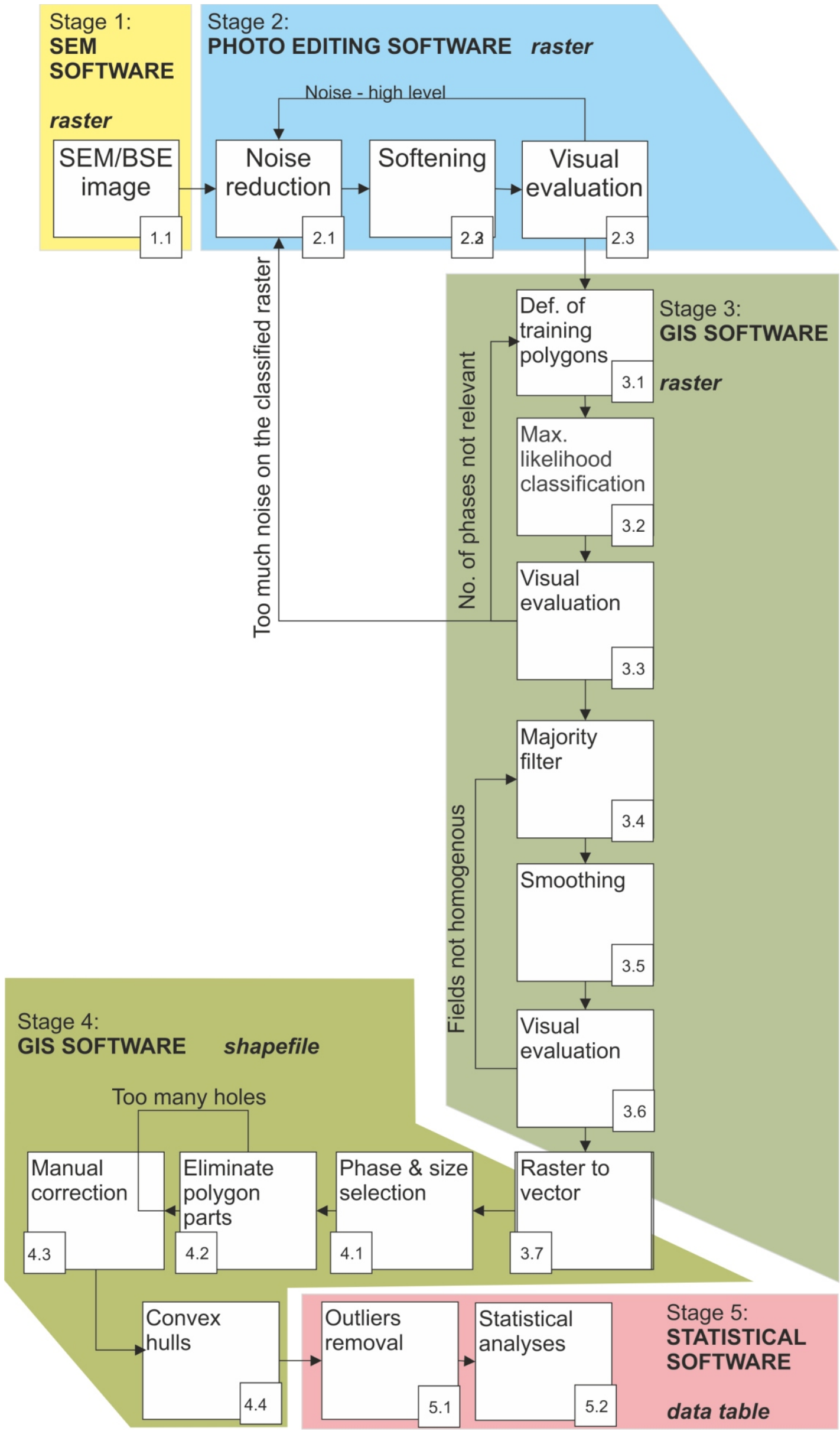

Fig. 3. Flowchart of the analytical procedure applied 

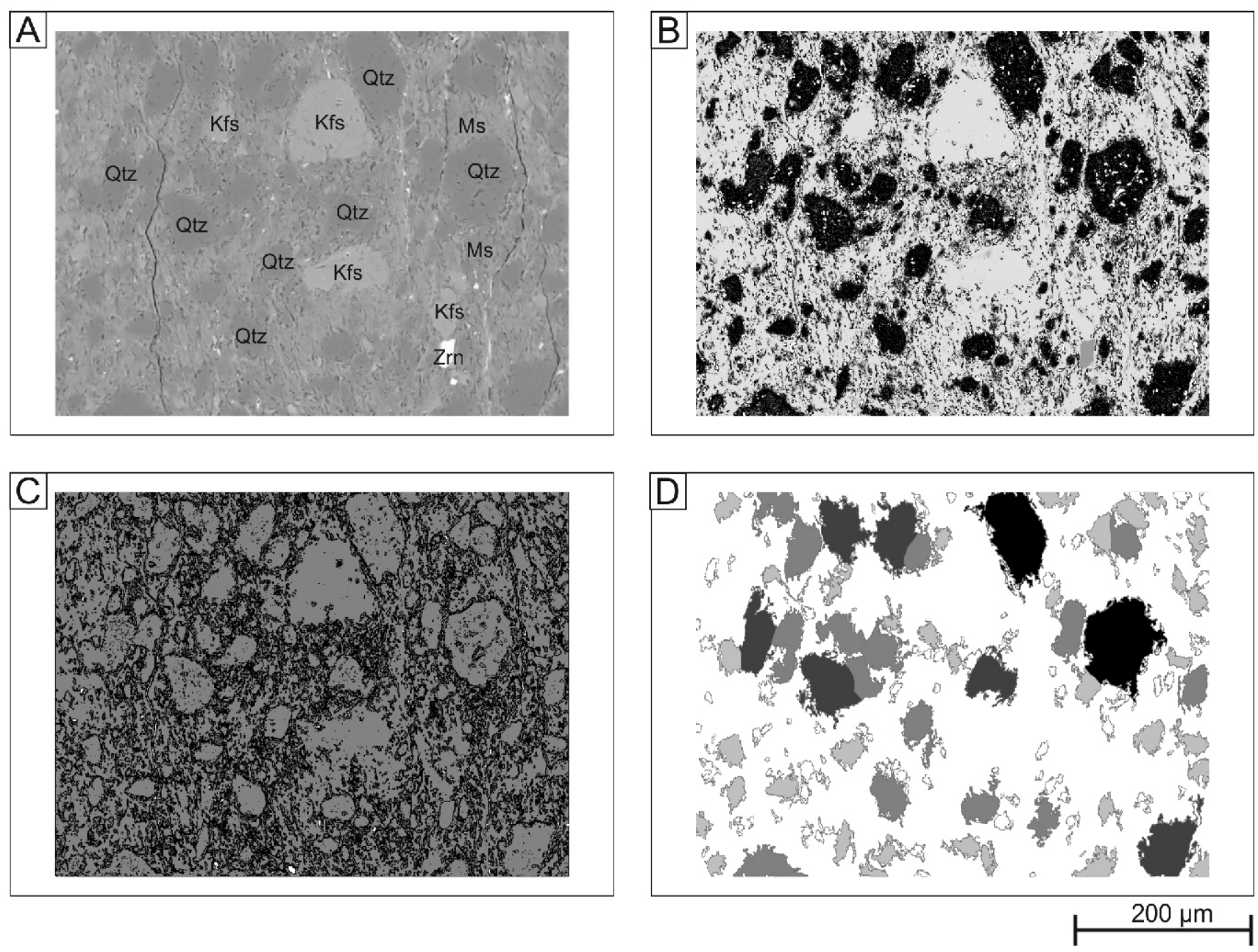

Fig. 4. Example of data processing (sample 43)

A - raw SEM-BSE image (Qtz - quartz, Kfs - K feldspar, Ms - muscovite, Zrn - zircon); B - classified image; quartz grains marked as black; C - all grains, vectorised image; D - grains selected to analyse (quartz); grey level corresponds to the grain area

(i.e. several pixels in size) eliminated (step 4.1; Fig. 4C). The "eliminate polygon parts" tool was applied to remove small holes and artefacts on grain borders; this was repeated, if necessary, with a different critical diameter (step 4.2).

Manual correction was indispensable (step 4.3). One of the main problems was that some of the grains (especially the larger ones) exhibited a tendency to become amalgamated with other grains in the processed image (Fig. 4D). This was corrected in the shapefile edition with a polygon-cutting tool. Additional corrections eliminated grains only partially contained by the image frame.

The data were then augmented by calculating the grain convex hulls (step 4.4) and exported as tables for further statistical analyses.

Outliers were defined based on the grain area. A median $\pm 3 \sigma$ (standard deviation) range was adopted for the analyses; other records were removed (step 5.1). Prior to the beginning of the statistical analyses (step 5.2), all of the dimensions became ArcGIS "undefined units". These units were finally recalculated in micrometres for linear dimensions or square micrometres for aerial dimensions based on calibration images with a scale bar acquired by the SEM Manager.
The equivalent circular diameter (ECD) parameter, applied as the main grain size indicator, is the diameter of a circle with the same area as the grain, calculated according to the following formula:

$$
\mathrm{ECD}=2 \times[(A) / \pi]^{1 / 2}
$$

where: $A$ is grain area.

The statistical analyses, which include descriptive statistics, a histogram, and scatter plots, were augmented with fractal dimension determination for grain size distribution.

Fractal dimensions were determined using the $R$ statistical computing language with the "fractaldim" package, which implements various methods for estimating fractal dimensions of numerical data (Sevcikova et al., 2014). The rodogram method of calculation (function fd.estim.rodogram()) was chosen because rodograms, which are modifications of variograms, are widely applied in geostatistical distance measurement, and can potentially eliminate the influence of reduction outliers or chaotic values on the analysis (Journel, 1988). 


\section{RESULTS}

The ratio of the grain perimeter to the grain area is one of the simplest shape indicators. When the dimensions are increasing, with a simple (convex) shape of the grain area preserved, the ratio should decrease, with a linear trend when plotting in log-log space. When the grain boundary is more complicated, with any indents or irregularities, the value rises, and the trend becomes non-linear. Measured ratios are shown on the log-log space scatter plots in Figure 5, clearly showing deviations from the linear trend. In fault rocks, the deviation of the trend can thus be interpreted as reflecting the presence of boundaries formed before cataclasis, in high-temperature grain boundary migration (Passchier and Trouw, 2005), one of the processes which can be responsible for creating loboid grain boundaries. This main sequence is always observed to have two parts: large and small grains. The border between them is clear in all cases. In all samples, the main sequence in the small grains shows some deviations in the log-log linear mode: there is always one subpopulation, or more, of small grains forming a "tail" on the scatter plot, where an increase in area is combined with a very small increase in the perimeter, or none, signifying that these grains have become straighter than others.

The grain size distribution is described using their circular equivalent diameter (ECD) with common descriptive statistics parameters (Fig. 5 and Table 2). The ECD values vary within a range of $0.003-236.33 \mu \mathrm{m}$, with a mean of $6.91 \mu \mathrm{m}$, for all of the grains analysed in an aggregate. Cataclasite 58 from Derava Pass and mylonite 72 from Siwa Pass are characterized by the widest range of ECD variation, with variance coefficients of 275.03 and 247.02, respectively. At the opposite extreme, the other Siwa Pass mylonite specimen, 68 , shows a variance of 47.68. This quantitative result closely correlates with the optical microscopy observations, according to which mylonite 68 is composed of a very fine grained matrix and rare large porphyroclasts. This is also the sample with the smallest maximum ECD value $(57.38 \mu \mathrm{m})$.

In all cases, the distribution is characterized by positive skewness (the third moment of distribution) within the range 4.10-7.13. Sample $68 \mathrm{a}$ is characterized by the least degree of skewness, due to the presence of a left-sided distribution tail this is also the sample with the lowest value of standard deviation.

The kurtosis (the fourth moment of distribution) values are extremely high, 20.37 to 78.47 (the distribution is strongly leptokurtic). Such high kurtosis values are explained by more than one high, sharp peak, especially in the distribution tail part (right side of the histogram).

The statistical distribution of the grain sizes can be interpreted as a marker of the "textural maturity" as the strain or comminution leads eventually to a log-normal distribution (An and Sammis, 1994). Fits to commonly used statistical distributions - half-normal, log-normal, and gamma distributions - were tested. The log-normal distribution shows the best fit for all samples; however, this fit varies between samples. Fitting accuracy was tested using the chi-square test by the Statistica software algorithm for number of degrees of freedom. The results were compared with a table of critical values (commonly available from statistical textbooks or websites). The results (Table 3) show that in one sample, the distribution fits a log-normal distribution quite closely (sample 58); in another sample (72) the fit is still quite close. All other samples show poor fits. The two samples mentioned above (58 and 72) are also those with the highest variance coefficients.
The fractal dimension $(d)$ parameter, sometimes called "mass dimension", is a measure of the self-similarity (Blenkinsop, 1991; Anderson et al., 1997; Bagde et al., 2002; Sammis and King, 2007) of the grain population analysed in two-dimensional space. In other words, it shows the degree to which the grain size distribution is self-similar (scale invariant; e.g., Bagde et al., 2002; Heilbronner and Keulen, 2006). The fractal dimension is another way to describe grain size distribution. If $0<d<2$ the distribution can be described as fractal; however, the GSD is often fractal in the small grains set and non-fractal in the larger grains set (Keulen et al., 2007).

In all of the samples, fractal dimensions were analysed for the entire population of grains as well as for two subsets: small and large grains. The boundary of the two subsets was determined using ECD histogram (Fig. 5) analyses and located at 10-30 $\mu \mathrm{m}^{2}$ ECD (Table 4).

The results are shown in Table 4. The all-data fractal dimensions are, in all but one case (i.e. in 58 cases) significantly smaller than the subset values. The smaller values generally indicate distributions closer to self-similarity; however, this will be discussed later. For all grains, the values are lowest in the mylonitic rocks (72 and Za2); moreover, in sample 72, the large grain subset closely fits the self-similarity trend. Samples 58 and $68 \mathrm{a}$ are at the opposite extreme, with high $d$ values, especially in the large grain subset. Sample 58 is also atypical, with the fractal dimensions of all grains higher than the small grain subset. In fact, the grain distribution characteristic of this rock is the most complicated, as will be shown in the discussion.

\section{DISCUSSION}

\section{APPLIED METHODOLOGY}

The methodology applied here seems very convenient, especially given the use of popular software and well-established analytical methods. However, it certainly needs more testing. The results for the rocks presented in this paper have been compared to the results for deformed granitic rocks obtained by Keulen et al. (2007; Table 5). The base images used in their study were SEM-BSE images; instead of a single image, as in the present study, they used sets of images within a range of magnification of 100-20,000x. Their software and grain detection methods were also different. Despite the methodological differences, the results obtained seem generally comparable.

\section{GRAIN SHAPES AND GRAIN SIZE DISTRIBUTION}

Deformations are multi-stage processes and occurs in different and changing conditions. The approach described (shape analysis, self similarity of grain size distribution) is then capable of helping distinguish between brittle and ductile deformation: the ductile stage is marked by the presence of lobate grain boundaries. Grain shape indicators, even such simple ones as the grain area vs. grain perimeter used in this study records this by deviating from a linear trend when plotted in log-log space (Fig. 6) Thus, it can be concluded that ductile processes, i.e. dynamic recrystallization, played an important role during grain evolution. As grain boundary migration is a process forming lobate shapes, the recrystallization should be considered as high-temperature recrystallization at temperatures above $500^{\circ} \mathrm{C}$ (Passchier and Trouw, 2005).

On the other hand, concurrent brittle and ductile processes, as well as grain reduction and tectonic growth, affect the grain 

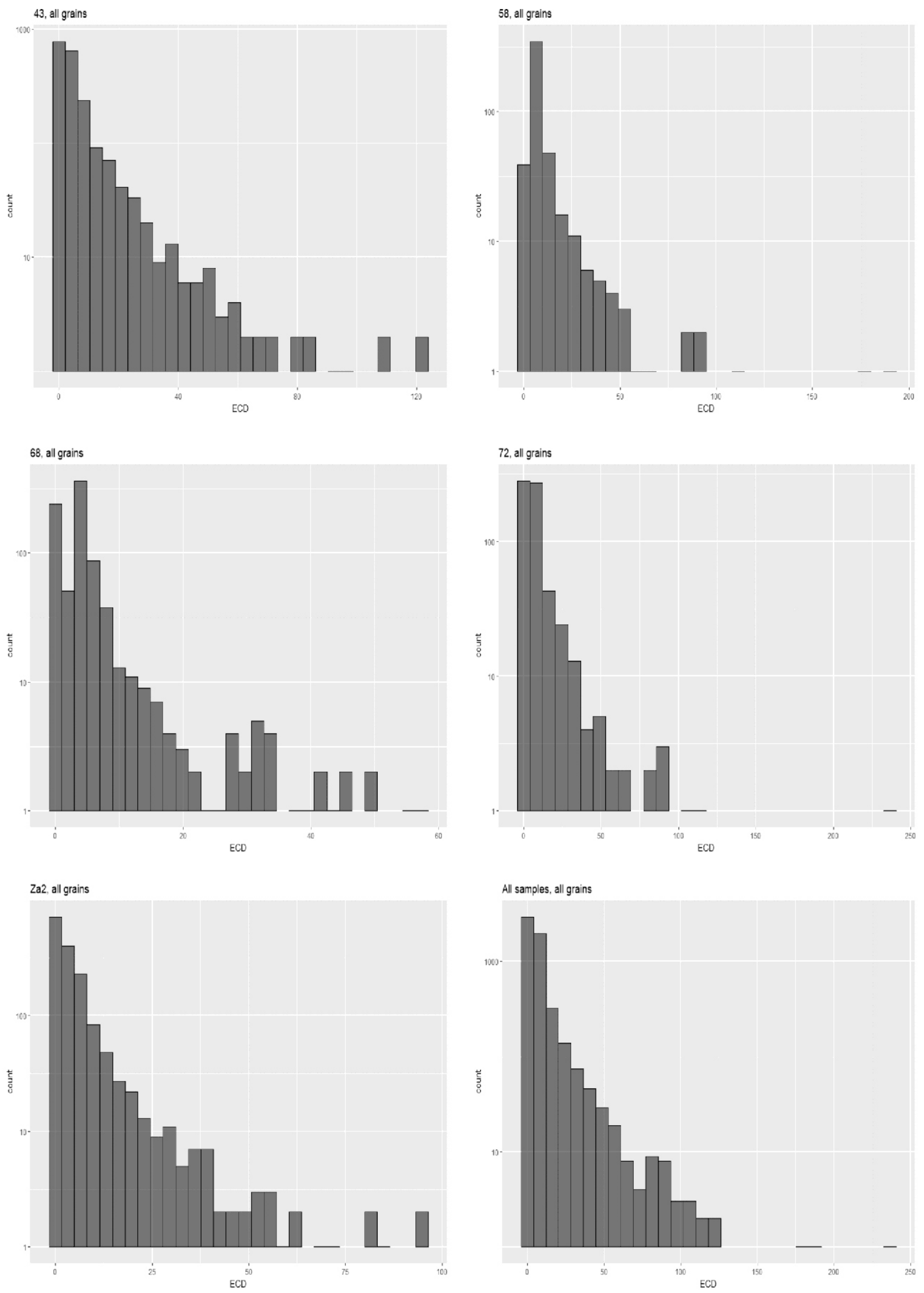

Fig. 5. Histograms of the grains equivalent circular diameter (ECD) 
Descriptive statistics of the equivalent circular diameter

\begin{tabular}{|c|c|c|c|c|c|c|c|c|c|}
\hline \multirow{2}{*}{ Sample } & \multirow{2}{*}{$\mathrm{N}$} & Mean & Media & Min & Max & Var & Std. Dev. & Skew. & Kurt. \\
\hline & & \multicolumn{8}{|c|}{ all values in $\mu \mathrm{m}$} \\
\hline \multicolumn{10}{|c|}{ All grains } \\
\hline 43 & 1984 & 6.632 & 3.990 & 0.004 & 121.832 & 126.728 & 11.257 & 4.511 & 29.105 \\
\hline 58 & 490 & 9.835 & 5.365 & 0.016 & 189.957 & 275.031 & 16.584 & 6.441 & 54.638 \\
\hline $68 a$ & 860 & 4.721 & 3.643 & 0.003 & 57.385 & 47.678 & 6.905 & 4.099 & 20.372 \\
\hline 72 & 655 & 8.142 & 4.552 & 0.010 & 236.331 & 247.024 & 15.717 & 7.135 & 78.475 \\
\hline Za2x & 1599 & 5.226 & 3.367 & 0.003 & 94.766 & 87.277 & 9.342 & 4.566 & 28.413 \\
\hline \multicolumn{10}{|c|}{ Small grains subset (up to tens of $\mu \mathrm{m}$, defined for each samples separately, see slope break value in Table 4 ) } \\
\hline 43 & 1913 & 4.952 & 3.869 & 0.004 & 29.665 & 34.716 & 5.892 & 1.814 & 3.370 \\
\hline 58 & 462 & 6.716 & 5.172 & 0.016 & 27.901 & 23.752 & 4.874 & 1.831 & 3.850 \\
\hline $68 a$ & 800 & 3.180 & 3.582 & 0.003 & 11.344 & 5.777 & 2.404 & 0.466 & 0.129 \\
\hline 72 & 633 & 5.907 & 4.410 & 0.010 & 35.191 & 43.426 & 6.590 & 2.006 & 4.573 \\
\hline Za2x & 1537 & 3.732 & 2.608 & 0.003 & 23.496 & 20.376 & 4.514 & 1.836 & 3.715 \\
\hline \multicolumn{10}{|c|}{ Large grains subset (hundreds to thousands of $\mu \mathrm{m}$, defined for each samples separately, see slope break value in Table 4 ) } \\
\hline 43 & 70 & 52.19 & 45.05 & 30.196 & 121.832 & 488.480 & 22.102 & 1.583 & 2.049 \\
\hline 58 & 28 & 61.29 & 44.29 & 29.126 & 189.957 & 1663.610 & 40.787 & 2.104 & 4.307 \\
\hline $68 a$ & 60 & 25.26 & 20.90 & 11.624 & 57.385 & 154.559 & 12.432 & 0.852 & 0.201 \\
\hline 72 & 22 & 72.42 & 58.22 & 36.492 & 236.331 & 1906.730 & 43.666 & 2.721 & 9.344 \\
\hline Za2x & 62 & 42.27 & 36.08 & 24.415 & 94.766 & 322.618 & 17.962 & 1.433 & 1.456 \\
\hline
\end{tabular}

Chi-square test result for the ECD values for log-normal distribution

\begin{tabular}{|l|c|c|c|c|}
\hline \multicolumn{1}{|c|}{ Sample } & Adjusted df & Chi-square & CV(df) & CV(df)/chi-square ratio \\
\hline 43 & 7 & 57.9 & 14.1 & 0.24 \\
\hline 58 & 3 & 9.6 & 7.8 & 0.81 \\
\hline $68 a$ & 5 & 55.3 & 11.1 & 0.20 \\
\hline 72 & 4 & 15.1 & 9.5 & 0.63 \\
\hline Za2 & 6 & 72.5 & 12.6 & 0.17 \\
\hline
\end{tabular}

$\mathrm{df}$ - number of degrees of freedom, $\mathrm{CV}(\mathrm{df})$ - critical value of chi-square for given df value

Table 4

Fractal dimensions of the ECD and slope break values

\begin{tabular}{|l|c|c|c|c|}
\hline Sample & All data fractal dimension & $\begin{array}{c}\text { Small grains subset fractal } \\
\text { dimension }\end{array}$ & $\begin{array}{c}\text { Large grains subset fractal } \\
\text { dimension }\end{array}$ & Slope break value $(\mu \mathrm{m})$ \\
\hline 43 & 1.83 & 1.89 & 1.99 & 30.5 \\
\hline 58 & 1.98 & 1.86 & 2.18 & 28.5 \\
\hline $68 \mathrm{a}$ & 1.96 & 2.00 & 2.25 & 11.5 \\
\hline 72 & 1.76 & 1.85 & 1.76 & 35.5 \\
\hline Za2 & 1.75 & 1.87 & 2.06 & 23.7 \\
\hline
\end{tabular}


Comparison of methods and some results

\begin{tabular}{|l|c|c|}
\hline & Keulen et al. (2007) & Kania (this study) \\
\hline Imaging method & SEM-BSE & SEM-BSE \\
\hline Magnification & $100 \times-20 \mathrm{k} \times ; 2-2.5$ step & $250 x$ \\
\hline Image analysis software & Image SXM + ImageJ & ArcGIS \\
\hline Grain detection & density slicing & maximum likelihood classification \\
\hline Phases identified & feldspars, quartz & matrix (incl. feldspars), quartz \\
\hline Grains per sample & $300-1200$ & $490-1984$ \\
\hline Diameter range $[\mu \mathrm{m}]$ & $0.06-400$ & $0.03-236$ \\
\hline Fractal dimension ranges & $1.4-2.3$ & $1.62-2.33$ \\
\hline
\end{tabular}

size distribution pattern. The change in grain size $(\Delta D)$ during tectonic processes can be described as (Cross et al., 2015):

$$
\Delta D=\Delta D_{\text {growth }}-\Delta D_{\text {reduce }}
$$

where: $\Delta D$ is the effect of two opposing components, growth and reduction.

However, when ductile and brittle processes co-occurring in the same deformation phase (brittle-ductile deformation regime, Passchier and Trouw, 2005) are taken into account, this equation can be upgraded to be more specific:

$$
\Delta D=\Delta D_{\text {growth }}-\left(\Delta D_{\text {crushing }}+\Delta D_{\text {dynamic_recrystalization }}\right)
$$

Thus the grain reduction component includes two sub-components: "cataclastic" and "mylonitic". Note that these are limited to stress-related processes; grain reduction can also be improved by other factors, such as sericitisation, which are also post-tectonic active processes.

Grain population characteristics are an important source of information concerning which of the processes described above were active during multiphase deformation (e.g., Heilbronner and Keulen, 2006; Keulen et al., 2007). In a paper by Kania (2014), it was shown, based on analyses of shape factors, that the main processes operating during deformation were cataclastic grain reduction, cataclastic flow, sericitisation, and - linked with sericitisation - the leaching, transport, and deposition of silica. At present, by aggregating the grain size data, we can see two grain populations in all samples (Fig. 6). Small-grain populations are especially well-developed in samples Za2 and 43. Sample 43 (cataclasite) shows that these grains may be the product of grain crushing. Therefore, it is possible that, in other samples as well, the presence of a smaller subset demonstrates the "cataclastic" sub-component in grain reduction processes. However, as this paper focuses on demonstrating some new methods and potential interpretations, this issue will have to remain open.

\section{FRACTALITY OF STRUCTURE}

According to the "constrained comminution" particle-size distribution model provided by Sammis et al. (1987) and Sammis and King (2007), the fractal dimension (fractal, mass dimension, considered two-dimensional in this paper) value during deformation is governed by the relative difference in size between neighbouring particles. This model shows that the brittle deformation process in the rock differs from e.g. crushing material in a mill, where initial size distribution governs output.
In general, the trend in textural evolution is to eliminate neighbouring same-size particles, as experimentally shown by Biegel et al. (1989) and modelled, using computers, by Steacy and Sammis (1991). The final texture should then be characterized by minimal dilation (optimal grain packing) and can be mathematically illustrated as a Sierpiński carpet (see e.g., Ciesielski and Pogoda, 1996) fractal for which $d=1.89$, or - even better a Sierpiński gasket (triangle) fractal for which $d=1.58$ - nearest to $d=1.6$, resulting in minimal dilation and therefore promoting the development of highly strained cataclasites. The important feature of the Sierpiński gasket is that no same-size particles are neighbours on any scale, which is also a result of the grain fragmentation process (Sammis, 1997) "constrained comminution" model described above. Natural grain aggregates in fault rocks are characterized by values of $d=2.0$ for the fault zone core and $d=1.6$ for the fault gauge zone (Chester et al., 2005; Sammis and King, 2007).

To determine whether the sample-size distribution is really self-similar, the number of magnitude orders covered by the analysis is important. In this study, there is only one order in the large subset, but there are four in the small subset. The distribution can be identified as self-similar if a frequency vs size log-log plot forms a straight line over several orders of magnitude (Keulen et al., 2007). In this study (Fig. 7), the grain size distribution samples Za2 and 72 (both mylonites) can be identified as the most nearly self-similar, at least in the small subset, where the straight section of the log-log distribution curve covers 2.5-3 orders of magnitude. Keulen et al. (2007) concluded that none of their samples was self-similar. It should be noted that they analysed all minerals. Perhaps, however, separate determination of the fractal dimension for each mineral phase is a better idea, due to the different mechanical properties of minerals.

Keeping the above in mind, it may be useful to introduce the factor of "textural maturity" in the deformed rocks, which can be described as a state of equilibrium between grain growth and grain reduction. Although such an ideal state seems impossible to obtain, the deforming processes may be moving asymptotically towards this state. The final state would be characterized, as was shown, by a fractal dimension with a value of $\sim 1.6$, resulting in the best packing. Textural maturity of this kind is also expressed by a high degree of statistical variance and a close log-normal fit. Moreover, increased textural maturity can make further (post-tectonic) grain reduction or alternating processes more difficult to accomplish, due to the greater difficulty of penetrating texturally well-packed rock.

Generally, the fractal dimensions obtained in this study are smaller in the small grains subset than with large grains. Moreover, small-grain self-similarity is marginally greater when only small grains are taken instead of the entire sample (Fig. 8). 
43 all data

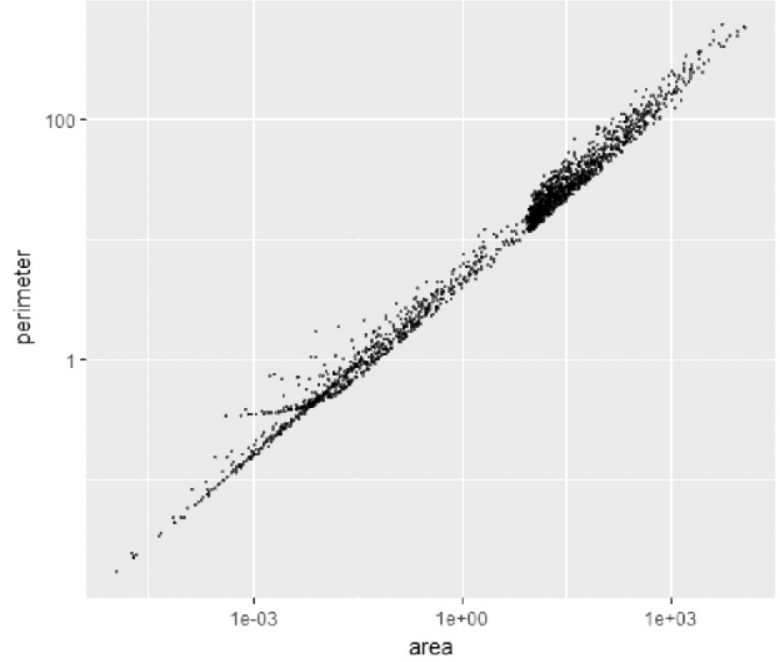

68 all data
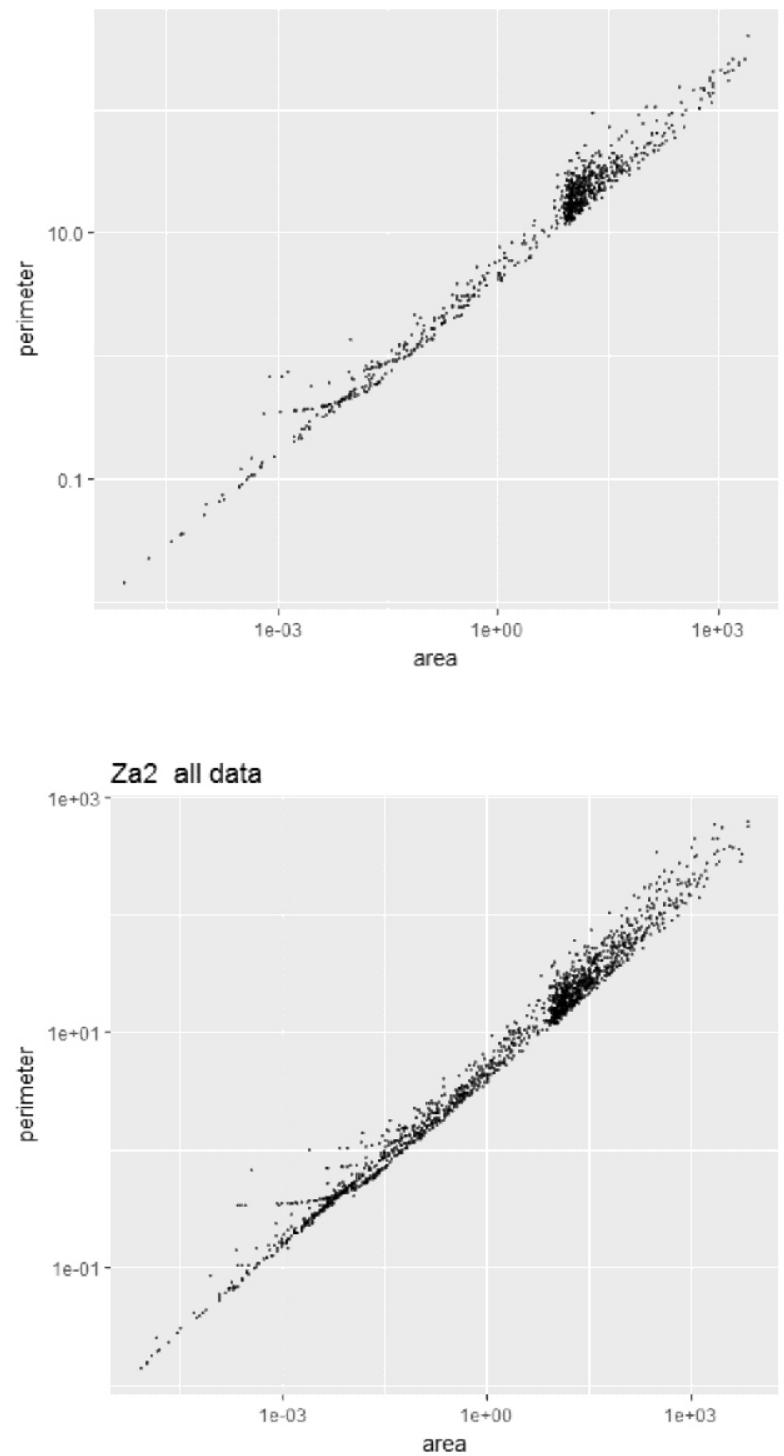

58 all data

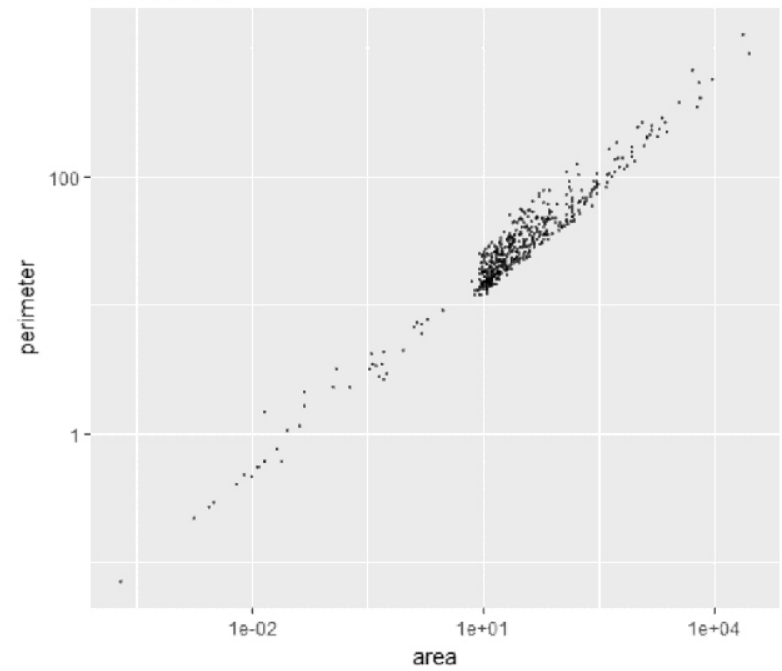

72 all data

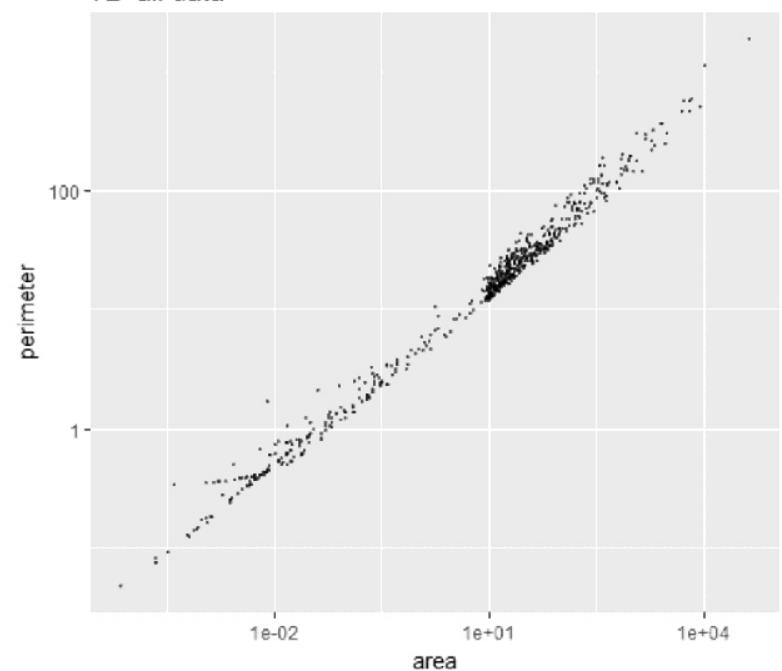

All samples all data

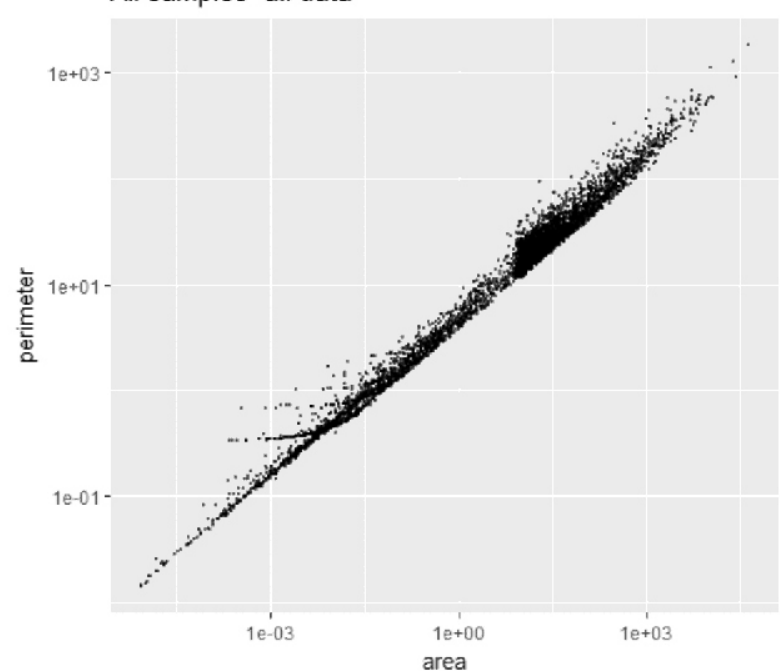

Fig. 6. Scatterplots of grain area vs. grain perimeter 


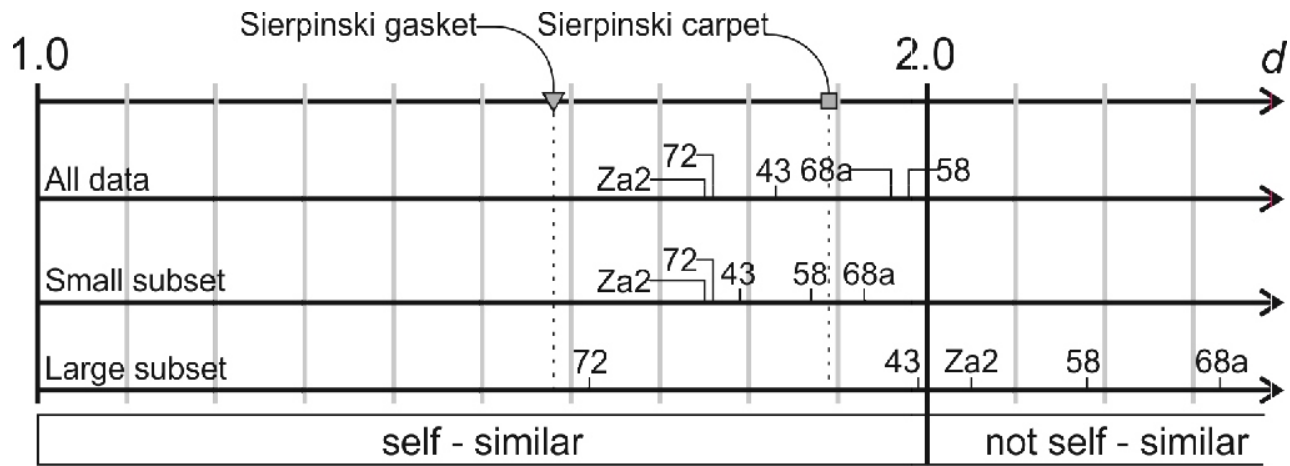

Fig. 7. Self-similarity of the samples with small- and large-grain subsets illustrated as fractal-dimension (d) calculated with the rodogram method on the number of axes

Additionally fractal dimensions of the Sierpiński gasket and carpet are marked
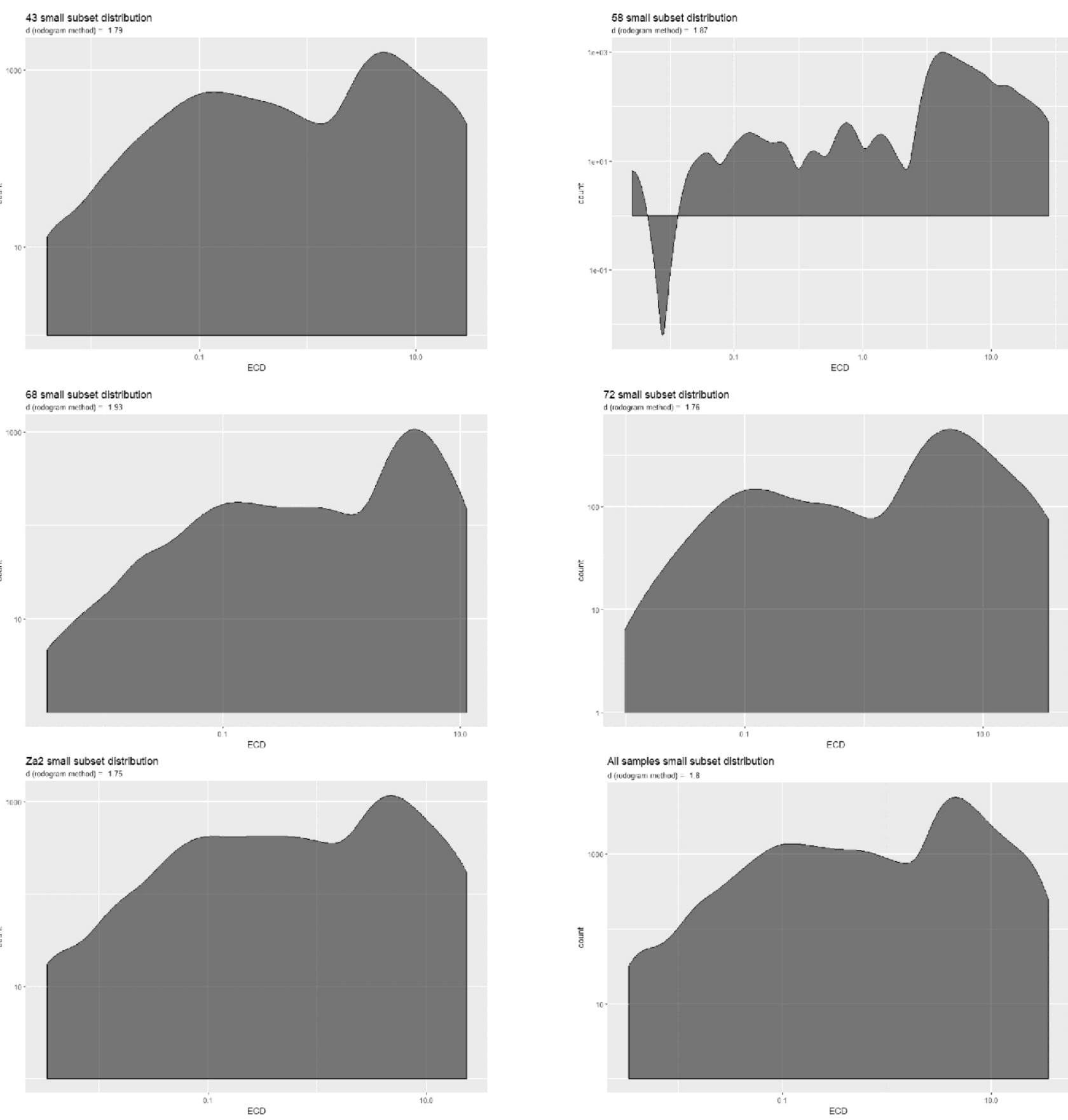

Fig. 8. Distribution curves of small grain subsets plotted in log-log space 
If a higher value of the fractal dimension is an indicator of a more mature size distribution texture, then a problem arises as to how to understand the fact that distribution is not homogenous, i.e. that subsets with differing fractal dimension values are present. Bjørk, et al. (2009) suggest a switch in the deformation mechanism during tectonic history. A switch of this kind may be an important event during the deformation history of the rocks analysed and may indicate a change from a Variscan ductile deformation regime to an Alpine brittle-ductile regime (Gawęda and Burda, 2004; Jurewicz and Bagiński, 2005; Kania, 2014), which may be marked by self-similarity (fractal dimension) differences between subsets of large and small grains.

\section{CONCLUSIONS}

1. The methodological approach presented is a relatively inexpensive and quick method to analyse grain size distribution in microscale as well as grain shape indicators. Such an analysis is helpful in determining what kind of processes (brittle or ductile) were active during deformation history. In particular, more value is added via the possibility to obtain repeatable results and fully quantitative data, which may be analysed with statistical procedures.

2. Observed self-similarity of the smaller grains subset may be explained as a product of advanced deformation in the brittle regime. According to the "constrained comminution" model, such a deformation should lead to the best packing of particles. The self-similarity level should be below 2 as is observed in the samples analysed.

3. The constrained data obtained generally shows two grain size subdistributions, with self-similar distribution in the smaller grain sets (fractal dimensions 1.85-2.00), and mixed distribution in the large grain set (fractal dimensions 1.76-2.25). These are typical values for natural grain size aggregates.

4. Image analysis based on the maximum likelihood classification is a tool applicable to SEM-EDS images. The results are comparable to the density slicing grain detection of Keulen et al. (2007).

Acknowledgements. I am grateful to $M$. Kohút and an anonymous reviewer for their patience and advice to improve this paper. Also I thank A. Lewandowska for support via the motivation I got from her. This study was financed with the Jagiellonian University young scientists' grant, 2015-17.

\section{REFERENCES}

An, L., Sammis, C., 1994. Particle size distribution of cataclastic fault materials from Southern California: A 3-D study. Pure and Applied Geophysics, 143: 203-227.

Anderson, A.N., McBratney, A.B., Crawford, J.W., 1997. Applications of Fractals to Soil Studies. Advances in Agronomy, 63 $1-76$.

Bac-Moszaszwili, M., Burchart, J., Głazek, A., Iwanow, A., Jaroszewski, W., Kotański, Z., Lefeld, J., Mastella, L., Ozimkowski, P., Roniewicz, P., Skupiński, A., Westwalewicz-Mogilska, E., 1979. Geological Map of the Polish Tatra Mountains (in Polish with English summary). Wyd. Geol. Warszawa.

Bagde, M.N., Raina, A.K., Chakraborty, A.K., Jethwa, J.L., 2002. Rock mass characterization by fractal dimension. Engineering Geology, 63: 141-155.

Biegel, R.L., Sammis, C.G., Dieterich, J.H., 1989. The frictional properties of a simulated gouge having a fractal particle distribution. Journal of Structural Geology, 11: 827-846.

Bjørk, T.E., Mair, K., Austrheim, H., 2009. Quantifying granular material and deformation: advantages of combining grain size, shape, and mineral phase recognition analysis. Journal of Structural Geology, 31: 637-653.

Blenkinsop, T.G., 1991. Cataclasis and processes of particle size reduction. Pure and Applied Geophysics, 136: 59-86.

Chester, J.S., Chester, F.M., Kronenberg, A.K., 2005. Fracture surface energy of the Punchbowl fault, San Andreas system. Nature, 437: 133-136.

Ciesielski, K., Pogoda, Z., 1996. The beginning of Polish topology The Mathematical Intelligencer, 18: 32-39.

Cross, A.J., Ellis, S., Prior, D.J., 2015. A phenomenological numerical approach for investigating grain size evolution in ductiley deforming rocks. Journal of Structural Geology, 76 22-34.

Cymerman, Z., 2009. Tektonika alpejska waryscyjskiego krystaliniku Tatr Zachodnich - przykłady od Łuczniańskie Przełęczy po NW zbocza Wołowca - Wycieczka terenowa A5 (in Polish). In: LXXIX Zjazd Polskiego Towarzystwa Geologicznego "Budowa geologiczna Tatr i Podhala ze szczególnym uwzględnieniem zjawisk geotermalnych na Podhalu", Bukowina
Tatrzańska, 26-29 września 2009, materiały konferencyjne: 121-133.

Cymerman, Z., 2010. Crystalline nappe sheets from the Polish part of the Western Tatra Mts. (in Polish with English summary). IV Konferencja Przyroda Tatrzańskiego Parku Narodowego a Człowiek - Nauka a Zarządzanie Obszarem Tatr i Ich Otoczeniem. Zakopane, 14-16 Październik 2010: 47-53 https://tpn.pl/filebrowser/files/T1 06.pdf

Deditius, A., 2004. Characteristics and isotopic age of the muscovite blastesis from the mylonitic zones in the crystalline rocks of the Western Tatra Mountains (in Polish with English summary). Prace Naukowe Uniwersytetu Śląskiego, 16: 121-150.

Fritz, H., Neubauer, F., Janák, M., Putiš, M., 1992. Variscan midcrustal thrusting in the Carpathians II: kinematics and fabric evolution of the Western Tatra basement. Terra Abstract, Supplement 2 to Terra Nova, 4: 24.

Gawęda, A., 2008. An apatite-rich enclave in the High Tatra granite (Western Carpathians): petrological and geochronological study. Geologica Carpathica, 59: 295-306.

Gawęda, A., Burda, J., 2004. Evolution of the metamorphism and deformations in the crystalline complex of the Western Tatra Mountains (in Polish with English summary). Prace Naukowe Uniwersytetu Sląskiego, 16: 53-184.

Gökyer, E., 2013. Understanding Landscape Structure Using Landscape Metrics. In: Advances in Landscape Architecture (ed. M. Özyavuz). InTech.

Hassanpour, A., 2012. The use of ArcGIS for determination of quartz optical axis orientation in thin section images. Journal of Microscopy, 245: 276-287.

Heilbronner, R., 2000. Automatic grain boundary detection and grain size analysis using polarization micrographs or orientation images. Journal of Structural Geology, 22: 969-981.

Heilbronner, R., Keulen, N., 2006. Grain size and grain shape analysis of fault rocks. Tectonophysics, 427: 199-216.

Ismat, Z., Mitra, G., 2005. Folding by cataclastic flow: evolution of controlling factors during deformation. Journal of Structural Geology, 27: 2181-2203.

Janák, M., 1994. Variscan uplift of the crystalline basement, Tatra Mts., central western Carpathians: evidence from ${ }^{40} \mathrm{Ar} /{ }^{39} \mathrm{Ar}$ laser 
probe dating of biotite and P-T-t paths. Geologica Carpathica, 45: 293-300.

Journel, A.G., 1988. New distance measures: the route toward truly non-Gaussian geostatistics. Mathematical Geology, 20: 459-475.

Jurewicz, E., 2005. Geodynamic evolution of the Tatra Mts. and the Pieniny Klippen Belt (Western Carpathians): problems and comments. Acta Geologica Polonica, 55: 295-338.

Jurewicz, E., Bagiński, B., 2005. Deformation phases in the selected shear zones within the Tatra Mountains granitoid core. Geologica Carpathica, 56: 17-28.

Kahan, Š., 1969. Eine neue Ansicht uber den geologischen Aufbau des Kristallinikums der West Tatra. Acta Geologica et Geographica Universitatis Comenianae, 12.

Kania, M., 2014. Microfabric diversity and grain shape analysis of fault rocks from the selected areas of the Western Tatra Mountains. Geological Quarterly, 58 (1): 3-18.

Keulen, N., Heilbronner, R., Stünitz, H., Boullier, A.-M., Ito, H., 2007. Grain size distributions of fault rocks: a comparison between experimentally and naturally deformed granitoids. Journal of Structural Geology, 29: 1282-1300.

Kohút, M., Janák, M., 1994. Granitoids of the Tatra Mts., Western Carpathians: field relations and petrogenetic implications. Geologica Carpathica, 45: 301-311.

Kohút, M., Poller, U., Gurk, C., Todt, W., 2008. Geochemistry and $\mathrm{U}-\mathrm{Pb}$ detrital zircon ages of metasedimentary rocks of the Lower Unit, Western Tatra Mountains (Slovakia). Acta Geologica Polonica, 58: 371-384.

Lin, A., 1999. S-C cataclasite in granitic rock. Tectonophysics, 304: 257-273.

Lin, A., 2001. S-C fabrics developed in cataclastic rocks from the Nojima fault zone, Japan and their implications for tectonic history. Journal of Structural Geology, 23: 1167-1178.

Nawrocki, J., Becker, A., 2017. Geological Atlas of Poland (in Polish). PIG-PIB, Warszawa.
Passchier, C., Trouw, R., 2005. Microtectonics, 2nd Revised Edition. Springer.

Piotrowska, K., 2016. Detailed geological map of the Tatra Mountains. Polish Geological Institute map server URL http://cbdgportal.pgi.gov.pl/smgt/.

Sammis, C.G., 1997. Fractal Fragmentation and Frictional Stability in Granular Materials. In: IUTAM Symposium on Mechanics of Granular and Porous Materials: Proceedings of the IUTAM Symposium Held in Cambridge, U.K., 15-17 July 1996 (eds. N.A. Fleck and A.C.F. Cocks): 23-34. Springer, Netherlands, Dordrecht.

Sammis, C.G., King, G.C.P., 2007. Mechanical origin of power law scaling in fault zone rock. Geophysical Research Letters, 34: L04312.

Sammis, C., King, G., Biegel, R., 1987. The kinematics of gouge deformation. Pure and Applied Geophysics, 125: 777-812.

Sevcikova, H., Percival, D., Gneiting, T., 2014. fractaldim: estimation of fractal dimensions. https://cran.r-project.org/package=fractaldim

Skupiński, A., 1975. Petrogenesis and structure of the crystalline core between Ornak and Rohacze, Western Tatra Mts (in Polish with English summary). Studia Geologica Polonica, 49: 1-105.

Steacy, S.J., Sammis, C.G., 1991. An automaton for fractal patterns of fragmentation. Nature, 353: 250-252.

Sun, J., Yang, J., Zhang, C., Yun, W., Qu, J., 2013. Automatic remotely sensed image classification in a grid environment based on the maximum likelihood method. Mathematical and Computer Modelling, 58: 573-581.

Śmigielski, M., Sinclair, H.D., Stuart, F.M., Persano, C., Krzywiec, P., 2016. Exhumation history of the Tatry Mountains, Western Carpathians, constrained by low-temperature thermochronology. Tectonics, 35: 187-207.

Tarquini, S., Favalli, M., 2010. A microscopic information system (MIS) for petrographic analysis. Computers and Geosciences, 36: 665-674. 